\title{
9
}

\section{Thawing the Chilly Climate: Inclusive Teaching Resources for Science, Technology, Engineering, and Math}

\author{
Katherine A. Friedrich, Sherrill L. Sellers, Judith N. Burstyn \\ University of Wisconsin-Madison
}

Although universities are aware of the need to promote diversity in science, technology, engineering, and mathematics (STEM), this awareness has not translated into significant changes in classroom environments. Many STEM instructors would like to offer equal opportunities for success to all of their students, but they are not sure where to begin. We describe an effective group of teaching tools that can empower STEM faculty and graduate students to modify their courses to address diversity at their own pace. These resources extend from awareness exercises to recommendations for action and have been useful tools for course design, teaching assistant training, and faculty development.

\footnotetext{
A lthough "diversity in the sciences" has become a common topic of discussion among university administrators and at funding agencies, inclusive teaching has not fully made its way into the college science classroom. Several scholars have suggested directions for this cultural shift (Riley, 2003; Rosser, 1993). However, in practice, science, technology, engineering, and mathematics (STEM) disciplines have been slow to change:

This response is not necessarily due to resistance from scientists. Many scientists with whom we have spoken do not view diversity awareness as essential to their teaching practice because they do not see the connections between diversity and their course content. Many others know that "diversity is important" but are not sure how to approach the topic.
} 
Faculty in technical fields face many challenges, especially when teaching large courses. The content they must convey is often complex and difficult for students to grasp intuitively. Because they need to focus on content delivery, faculty and teaching assistants (TAs) may not attend to the learning styles of their students. Research indicates that the learning styles of faculty and students often differ (Felder, 1996). Faculty traditionally tend to orient courses toward students who are introverted, are abstract thinkers, are logical rather than values oriented, and prefer definite solutions. However, many students do not fit this profile. If a faculty member assumes that his or her students learn best through listening to lectures, for example, he or she may find that students are not retaining the material.

Many STEM faculty and TAs are unaware of the exclusionary aspects of their courses. They are simply teaching their students the way they were taught. Subtle changes to teaching practices, especially in introductory courses, can make a difference for students who are still exploring their career choices. These are the students who are currently dropping out of STEM programs, and they are the ones we need to retain (Seymour \& Hewitt, 1997).

The Center for the Integration of Research, Teaching, and Learning (CIRTL) has developed resources to aid in creating discussion among faculty, initiating interventions, and improving classroom climate and course content. Recent evaluations of the resources suggest STEM faculty find the materials to be useful (Burstyn, Sellers, Friedrich, \& Gunasekera, 2006).

\section{Why Teach Inclusively?}

Encouraging inclusive teaching begins with awareness of the current situation of students from underrepresented groups.

Minority students of high potential often leave STEM fields. For example, African-American students are more likely than majority students to express interest in STEM careers, but few persist through graduate school to complete their Ph.D.s (Maton, Hrabowski, \& Schmitt, 2000). Bright students opt out of STEM for a variety of reasons (Seymour \& Hewitt, 1997), including the lack of creative engagement in introductory courses (Tobias, 1990), the lack of connection between science and social values (Rosser, 1993), and unwelcoming departmental cultures (Ferreira, 2002).

The problem of stereotypes transcends the classroom. Some studies show that children, even before entering preschool, already consider the typical scientist to be white and male (see Yanowitz, 2004). Students from underrepresented groups may be more likely to eschew a STEM degree because they 
doubt their technical competence in the face of stereotypes (Moore, MadisonColmore, \& Smith, 2003; Steele, 1997).

In this challenging, sometimes intimidating environment, faculty may be unaware that teaching for inclusion is more than a matter of changing pronouns, last names, or pictures on a PowerPoint slide. Inclusive teaching is a composite of good communication, cultural understanding, effective course design, fair grading, and awareness of interpersonal dynamics (Adams, Bell, \& Griffin, 1997; Davis, 1993).

College students from underrepresented groups face subtle challenges to their confidence and barriers to learning (Cabrera \& Nora, 1994). Grading often reflects verbal participation, which may be influenced by language or cultural differences. Returning students, international students, and students with disabilities face specific obstacles.

Alienation may be especially problematic for students who have difficulty forming study groups with their peers because of social or demographic differences. For instance, Treisman (1992) found that the underrepresented minority students who were not doing well in his mathematics courses were having difficulties, not because of academic preparation or motivation, but because they were not part of study groups. He initiated an honors program that encouraged students to collaborate on challenging problems in an environment of high expectations. The model has been so successful that it has spread to other universities and colleges throughout the country.

\section{Changing the Climate}

Treisman (1992) and others point the way to addressing these questions: What can instructors and administrators do to develop inclusive climates in STEM? And how can organizational developers work with them to accomplish this goal?

Three types of approaches emerged from the CIRTL Diversity Institute, a collaborative effort that brought together STEM faculty and diversity experts to develop resources for inclusive teaching. We group these approaches into the following categories:

- Raising awareness

- Developing intervention programs

- Supporting inclusive teaching 
All three prongs of this approach are important. Awareness-raising without action does not lead to sustained change. Intervention program development may address the immediate needs of students from underrepresented groups, but it does not change the culture that surrounds them. Awareness is needed to motivate inclusive teaching, and intervention programs are needed to complement inclusive practice.

\section{:Raising Awareness}

Faculty, instructional staff, TAs, and administrators can raise their awareness by reflecting on student experiences of diversity in the classroom. Sometimes, people discuss diversity only with others who will agree with them. Providing opportunities where people can disagree respectfully brings the conversation out into the open and raises the awareness of all participants. Organizational developers can create forums for these types of discussion. Clear ground rules are essential for these facilitated conversations.

One useful resource that we have developed is Case Studies in Inclusive Teaching in Science, Technology, Engineering, and Mathematics (Sellers, Friedrich, Gunasekera, Saleem, \& Burstyn, 2006). This collection of scenarios is designed to introduce educators to issues that faculty and students from underrepresented groups may face in STEM academic programs. The topics covered include nationality, race/ethnicity, gender, sexual orientation, disability, and academic preparation. Each case is written so that it can be addressed from a variety of perspectives. The case studies are presented together with discussion questions, worksheets for individual responses, and group facilitation instructions.

This book has been used successfully in workshops with a variety of audiences and at a range of institutions. For example, we have used these cases in TA training, in faculty development workshops, and with university administrators. We have conducted case-based workshops at research universities, community colleges, and national foundations. The case studies are also available on the Internet; in the future, we plan to produce several of them in a multimedia format.

We have found data, personal experiences, and self-tests to be useful in helping people step outside their usual perspectives and learn about the experiences of students from underrepresented groups. We synthesized these approaches in developing our online self-guided workshop (Sellers \& Friedrich, 2006), which contains resources that we found impressive in their honesty and directness. The workshop materials include self-tests for bias, reflective articles on racism, data on educational access and the U. S. labor force, videos on student experiences, and challenging exercises for group work. 


\section{Developing Intervention Programs}

Once faculty and administrators are aware of the disparities that exist, they may express interest in developing intervention programs. Interventioncreating specialized programs to help students from underrepresented groups succeed in STEM-is a popular method of improving student success and retention. The Diversity Institute literature review (Cabrera et al., 2004) indicates that some of the most successful programs emphasize mentoring, research experience, financial support, collaborative learning, and high expectations for all students (Barlow \& Villarejo, 2004; Cabrera et al., 2002; Maton et al., 2000; Stahl, 2005).

In recent years, many universities have created innovative programs to recruit and retain students from underrepresented groups. For example, the Meyerhoff Scholars Program provides extensive advising and career support for future Ph.D.s (Maton et al., 2000). Smith College has initiated a degree program in engineering for women and is pioneering innovative teaching strategies to engage students in critical thinking (Riley, 2003). Many institutions offer support programs for women in science and engineering. For example, the University of Wisconsin-Madison Women in Science and Engineering program is a residential learning community that encourages appreciation for science and the arts and has improved undergraduate STEM students' grades (Allen, 1999). National support programs in mathematics based on the work of Treisman (1992) have been particularly successful. The Wisconsin Emerging Scholars program, a multicultural intensive math program, has improved students' grades in calculus (Alexander, Burda, \& Millar, 1997).

\section{Supporting Inclusive Teaching}

It is important for faculty and TAs to understand that diversity and teaching excellence are intertwined. This concept is one of the core principles of CIRTL. Inclusive teaching is part of good instruction. Administrators and organizational developers can support faculty in experimenting with techniques and strategies to engage all students.

We developed the teaching manual Reaching All Students: A Resource for Teaching in Science, Technology, Engineering, and Mathematics (Sellers, Roberts, Giovanetto, \& Friedrich, 2005) with the intention of integrating inclusive practice throughout the educational process, from course planning through evaluation. Rather than being one chapter appended to the guide, diversity is woven throughout the text. We have compiled sections from many existing sources, including Tools for Teaching (Davis, 1993) and Science Teaching Reconsidered (National Research Council, 1997), and have authored additional material to 
create a concise handbook that is geared toward STEM instruction. Reaching All Students has been used in TA training and in new faculty development, as well as with university staff and experienced faculty.

Reaching All Students is structured around the lifecycle of a course and includes information on the following:

- Course planning guidelines that allow instructors to begin a course in a way that "reaches all students." Inclusion can be accomplished through thoughtful selection of course materials, development of student-friendly syllabi, and outcomes-oriented course planning (also known as "backwards design").

- Recommendations for communicating effectively with students, developing rapport, addressing misconceptions about science, discussing controversial topics, and communicating cross-culturally.

- Teaching methods that include students of diverse learning styles. There are many advantages to introducing active and interactive learning to supplement lecture methods. Within a lecture setting, there are also steps that one can take to encourage student confidence, interaction, and participation.

- Assessment and evaluation methods that provide useful and fair data on student experiences and knowledge. This information can be used to continuously improve course design.

The resources that we have compiled allow STEM instructors to gradually implement more strategies as they have time to do so. The literature review, for example, contains many recommendations for both faculty innovation and institutional change (Cabrera et al., 2004). From creating intervention and support programs to promoting collaborative learning, these actions can foster a welcoming environment for STEM students from underrepresented groups while also improving the academic climate for majority students.

\section{Conclusion}

Meeting the need for inclusive teaching requires both faculty and institutional commitment, and organizational developers and administrators play a vital role. Faculty will feel freer to experiment within their classrooms with institutional backing. More specifically, initial innovations may not be welcomed by students familiar with more traditional teaching methods; one possible outcome may be a short-term dip in teaching evaluations. Recent studies show that 
students who prefer a more didactic style of teaching, for example, may express discomfort with teaching methods that differ from what they expect (Kember, Jenkins, \& Ng, 2004; Kember \& Wong, 2000). It is the role of administrators and organizational developers to support their faculty through the transition to inclusive teaching methods. Institutional understanding can empower faculty to strive for teaching excellence, thus thawing out the chilly climate.

\section{Author Note}

Our resource development has been supported by the National Science Foundation, Grant 0227592. Any opinions, findings, and conclusions or recommendations expressed in this material are those of the authors and do not necessarily reflect the views of the National Science Foundation. We would like to acknowledge the contributions of the current and past members of the CIRTL diversity team, including Alberto Cabrera and Nilhan Gunasekera. Diversity Institute scholars from many universities contributed time and energy to this project. We also would like to thank CIRTL's leaders and staff for their support.

Correspondence concerning this chapter should be addressed to Katherine A. Friedrich, Center for the Integration of Research, Teaching, and Learning, University of Wisconsin-Madison, 552 Educational Sciences Building, Madison, WI 53706. Email: friedrich@wisc.edu.

\section{References}

Adams, M., Bell, L. A., \& Griffin, P. (1997). Teaching for diversity and social justice: A sourcebook. New York, NY: Routledge.

Alexander, B. B., Burda, A. C., \& Millar, S. B. (1997). A community approach to learning calculus: Fostering success for underrepresented ethnic minorities in an emerging scholars program. Journal of Women and Minorities in Science and Engineering, 3(3), 145-159.

Allen, C. (1999). Wiser women: Fostering undergraduate success in science and engineering with a residential academic program. Journal of Women and Minorities in Science and Engineering, 5(3), 265-277.

Barlow, A. E. L., \& Villarejo, M. R. (2004). Making a difference for minorities: Evaluation of an educational enrichment program. Journal of Research in Science Teaching, 41(9), 861-881.

Burstyn, J. N., Sellers, S. L., Friedrich, K. A., \& Gunasekera, N. (2006). [Workshop evaluations of CIRTL Diversity Resources]. Unpublished raw data. 
Cabrera, A. F., Crissman, J. L., Bernal, E. M., Nora, A., Terenzini, P. T., \& Pascarella, E. T. (2002, January/February). Collaborative learning: Its impact on college students' development and diversity. Journal of College Student Development, 43(1), 20-34.

Cabrera, A. F., Doyon, K., Friedrich, K., Roberts, J., Saleem, T., \& Giovanetto, L. (2004). Literature review. Retrieved May 16, 2007, from the University of WisconsinMadison, Center for the Integration of Research, Teaching and Learning web site: http://cirtl.wceruw.org/DiversityInstitute/resources/annotated\%2Dbibliography

Cabrera, A. F., \& Nora, A. (1994). College students' perceptions of prejudice and discrimination and their feelings of alienation: A construct validation approach. Review of Education/Pedagogy/Cultural Studies, 16(3-4), 387-409.

Davis, B. G. (1993). Tools for teaching. San Francisco, CA: Jossey-Bass.

Felder, R. M. (1996). Teaching to all types: Examples from engineering education. ASEE Prism, 6(4), 18-23.

Ferreira, M. M. (2002). The research lab: A chilly place for graduate women. Journal of Women and Minorities in Science and Engineering, 8(1), 85-98.

Kember, D., Jenkins, W., \& Ng, K. C. (2004, March). Adult students' perceptions of good teaching as a function of their conceptions of learning-Part 2. Implications for the evaluation of teaching. Studies in Continuing Education, 26(1), 81-97.

Kember, D., \& Wong, A. (2000, July). Implications for evaluation from a study of students' perceptions of good and poor teaching. Higher Education, 40(1), 69-97.

Maton, K. I., Hrabowski, F. A., \& Schmitt, C. L. (2000, September). African American college students excelling in the sciences: College and post-college outcomes in the Meyerhoff Scholars Program. Journal of Research in Science Teaching, 37(7), 629-654.

Moore, J. L., III, Madison-Colmore, O., \& Smith, D. M. (2003, Fall). The prove-themwrong syndrome: Voices from unheard African-American males in engineering disciplines. Journal of Men's Studies, 12(1), 61-73.

National Research Council. (1997). Science teaching reconsidered: A handbook. Washington, DC: National Academy Press.

Riley, D. (2003). Employing liberative pedagogies in engineering education. Journal of Women and Minorities in Science and Engineering, 9(2), 137-158.

Rosser, S. V. (1993). Female friendly science: Including women in curricular content and pedagogy in science. Journal of General Education, 42(3), 191-220. 
Sellers, S. L., \& Friedrich, K. A. (2006). Unmasking inequality: A self-guided workshop on educational success. Retrieved May 17, 2007, from the University of Wisconsin-Madison, Center for the Integration of Research, Teaching and Learning web site: http://cirtl.wceruw.org/DiversityInstitute/resources/workshops/

Sellers, S. L., Friedrich, K., Gunasekera, N., Saleem, T., \& Burstyn, J. (2006). Case studies in inclusive teaching in science, technology, engineering, and mathematics. Madison, WI: University of Wisconsin-Madison, Center for the Integration of Research, Teaching, and Learning.

Sellers, S. L., Roberts, J., Giovanetto, L., \& Friedrich, K. (2005). Reaching all students: A resource for teaching in science, technology, engineering, and mathematics. Madison, WI: University of Wisconsin-Madison, Center for the Integration of Research, Teaching, and Learning.

Seymour, E., \& Hewitt, N. M. (1997). Talking about leaving: Why undergraduates leave the sciences. Boulder, $\mathrm{CO}$ : Westview Press.

Stahl, J. M. (2005, January). Research is for everyone: Perspectives from teaching at historically black colleges and universities. Journal of Social and Clinical Psychology, 24(1), 85-96.

Steele, C. M. (1997). A threat in the air: How stereotypes shape intellectual identity and performance. American Psychologist, 52(6), 613-629.

Tobias, S. (1990, July/August). They're not dumb. They're different. A new "tier of talent" for science. Change, 22(4), 10-30.

Treisman, U. (1992, November). Studying students studying calculus: A look at the lives of minority mathematics students in college. College Mathematics Journal, 23(5), 362-372.

Yanowitz, K. L. (2004). Do scientists help people? Beliefs about scientists and the influence of prosocial context on girls' attitudes towards physics. Journal of Women and Minorities in Science and Engineering, 10(4), 393-399. 